\title{
Mechanisms of hepatocellular toxicity associated with new psychoactive synthetic cathinones
}

Dino Luethi, ${ }^{a, b, c}$, Matthias E. Liechti MD, MAS ${ }^{a, b, c}$, Stephan Krähenbühl, MD, PhD ${ }^{a, b, c}$

aDivision of Clinical Pharmacology \& Toxicology, University Hospital Basel, Basel, Switzerland

${ }^{b}$ Department of Biomedicine, University of Basel, Basel, Switzerland

'Swiss Centre of Applied Human Toxicology, Basel, Switzerland

\section{Corresponding author:}

Stephan Krähenbühl, MD, PhD

Clinical Pharmacology \& Toxicology

University Hospital

4031 Basel, Switzerland

Phone: +4161265 4715

Fax: +41612654560

e-mail: stephan.kraehenbuehl@usb.ch 


\section{Abbreviations}

ADP: adenosine-diphosphate

AK: adenylate kinase

BSO: buthionine sulfoximine

CYP: cytochrome P450

DMEM: Dulbecco's Modified Eagle Medium

DTNB: 5,5'-dithio-bis(2-nitrobenzoic acid)

FCCP: trifluoromethoxy carbonylcyanide phenylhydrazone

FCS: fetal calf serum

GR: glutathione reductase

GSH: glutathione (reduced)

GSSG: glutathione (oxidized)

KPE: potassium phosphate buffer

MDMA: 3,4-methylenedioxymethamphetamine

MDPV: 3,4-methylenedioxypyrovalerone

$\mathrm{O}_{2}^{-}$: superoxide

OCR: oxygen consumption rate

PBS: phosphate-buffered saline

PCA: perchloric acid

SRB: sulforhodamine B

TMRM: tetramethylrhodamine methyl ester

tGSH: glutathione (total)

$\beta$-NADPH: $\beta$-nicotinamide adenine dinucleotide 2'-phosphate

$\Delta \psi_{\mathrm{m}}:$ mitochondrial membrane potential 


\section{Abstract}

Synthetic cathinones are a new class of psychostimulant substances. Rarely, they can cause liver injury but associated mechanisms are not completely elucidated. In order to increase our knowledge about mechanisms of hepatotoxicity, we investigated the effect of five frequently used cathinones on two human cell lines. Bupropion was included as structurally related drug used therapeutically. In HepG2 cells, bupropion, MDPV, mephedrone and naphyrone depleted the cellular ATP content at lower concentrations $(0.2$ to $1 \mathrm{mM})$ than cytotoxicity occurred ( 0.5 to 2 $\mathrm{mM})$, suggesting mitochondrial toxicity. In comparison, methedrone and methylone depleted the cellular ATP pool and induced cytotoxicity at similar concentrations $(\geq 2$ mM). In HepaRG cells, cytotoxicity and ATP depletion could also be demonstrated, but cytochrome P450 induction did not increase the toxicity of the compounds investigated. The mitochondrial membrane potential was decreased in HepG2 cells by bupropion, MDPV and naphyrone, confirming mitochondrial toxicity. Bupropion, but not the other compounds, uncoupled oxidative phosphorylation. Bupropion, MDPV, mephedrone and naphyrone inhibited complex I and II of the electron transport chain, naphyrone also complex III. All four mitochondrial toxicants were associated with increased mitochondrial ROS and increased lactate production, which was accompanied by a decrease in the cellular total GSH pool for naphyrone and MDPV. In conclusion, bupropion, MDPV, mephedrone and naphyrone are mitochondrial toxicants impairing the function of the electron transport chain and depleting cellular ATP stores. Since liver injury is rare in users of these drugs, affected persons must have susceptibility factors rendering them more sensitive for these drugs.

Key words: New psychoactive substances, cathinones, liver injury, mitochondria, electron transport chain, ROS 


\section{Introduction}

In recent years, various synthetic cathinones ("bath salts", research chemicals) with amphetamine-like properties have emerged on the illicit drug market and have become popular alternatives to classic stimulants among drug users (Baumann et al., 2013; Prosser and Nelson, 2012). Cathinone designer drugs are derivatives of cathinone (Fig. 1), a naturally occurring $\beta$-keto-amphetamine found in the leaves of the Catha edulis plant, and are chemically and pharmacologically similar to classic illicit stimulants (Baumann et al., 2012; Rickli et al., 2015; Simmler et al., 2013; Simmler et al., 2014). Therefore, the health risks posed by synthetic cathinones may be similar to the classic stimulants (Liechti, 2015). A rare, but potentially severe adverse reaction of stimulant use is hepatotoxicity (Andreu et al., 1998; De Carlis et al., 2001; Ellis et al., 1996; Garbino et al., 2001; Jones et al., 1994; Kamijo et al., 2002). Most research concerning stimulant hepatotoxicity has so far focused on 3,4-methylenedioxymethamphetamine (MDMA; "ecstasy"). However, the hepatotoxic mechanism of MDMA is currently not entirely understood and multiple factors including polydrug abuse, hyperthermia, and metabolism appear to be associated with liver injury in MDMA users (Antolino-Lobo et al., 2011b; Carvalho et al., 2012; Dias da Silva et al., 2013a; Dias da Silva et al., 2013b). In comparison, data on hepatotoxicity of the newly used synthetic cathinones is currently scarce. A case of acute liver failure after synthetic cathinones use has been described (Fröhlich et al., 2011) and in vitro studies showed that mitochondrial dysfunction and oxidative stress contribute to hepatic injury associated with these compounds (Valente et al., 2016a; Valente et al., 2016b).

In the current study, we aimed to investigate in more detail the mechanisms of hepatocellular toxicity of several synthetic cathinones (Fig. 1) with a focus on mitochondrial toxicity. We therefore investigated the toxicity of the cathinone designer drugs 3,4-methylenedioxypyrovalerone (MDPV), 4-methylmethcathinone (4MMC; mephedrone), 4-methoxymethcathinone (4-MeOMC; methedrone), 3,4- 
methylenedioxymethcathinone ( $\beta \mathrm{k}-\mathrm{MDMA}$; methylone), and naphthylpyrovalerone (naphyrone) in two human hepatocyte cell lines. In addition, we included bupropion, a synthetic cathinone used as an antidepressant and as a smoking cessation aid.

\section{Methods}

\subsection{Test substances}

Naphyrone was synthesized as previously described by Meltzer et al. (Meltzer et al., 2006). Methylone, mephedrone, methedrone, and MDPV were purchased from Lipomed (Arlesheim, Switzerland) with HPLC purity of $>98.5 \%$. Bupropion was purchased from Cayman Chemicals (Ann Arbor, MI, USA), with a purity of $>98 \%$. All drugs were obtained as racemic hydrochloride salts. Drug stocks were made in autoclaved Milli-Q water and were freshly prepared for each assay.

\subsection{Cell line and culture}

The HepG2 cell line was obtained from the American Type Culture Collection (ATCC, Manassas, USA) and cultured in Dulbecco's Modified Eagle Medium (DMEM, $1 \mathrm{~g} / \mathrm{l}$ glucose) supplemented with $10 \%$ heat inactivated fetal calf serum (FCS), 10 mM HEPES buffer, 2 mM GlutaMAX ${ }^{T M}$, 1\% MEM non-essential amino acids, and penicillin-streptomycin $(10,000 \mathrm{U} / \mathrm{ml}$ corresponding to $10 \mathrm{mg} / \mathrm{ml})$. Cell culture medium and supplements were purchased from Invitrogen (Basel, Switzerland).

The HepaRG cell line was obtained from Biopredic International (Saint Grégoire, France) and cultured in William's E medium (no glutamine) supplemented with 10\% FCS, 2 mM L-glutamine, $50 \mu \mathrm{M}$ hydrocortisone hemisuccinate (Sigma Aldrich, Buchs, Switzerland), 0.05\% human insulin $(9.5-11.5 \mathrm{mg} / \mathrm{ml}$ insulin, Sigma Aldrich), and penicillin-streptomycin $(10,000 \mathrm{U} / \mathrm{ml}$ corresponding to $10 \mathrm{mg} / \mathrm{ml})$. The 
cells were cultured at $37{ }^{\circ} \mathrm{C}$ in a $5 \% \mathrm{CO}_{2}$ humidified atmosphere and passaged using trypLE ${ }^{\text {TM }}$ Express reagent (Invitrogen) when they reached $70-80 \%$ confluency.

\subsection{Cytotoxicity of HepG2 cells}

Cytotoxicity was assessed with the ToxiLight BioAssay Kit from Lonza (Basel, Switzerland) and conducted according to the manufacturer's manual. Briefly, 25,000 HepG2 cells per well were seeded in a 96-well plate. The following day, the cells were treated with $100 \mu \mathrm{l}$ of the test substances dissolved in medium $(0.01 \mathrm{mM}, 0.1$ $\mathrm{mM}, 1 \mathrm{mM}$, and $2 \mathrm{mM}$ for each drug and additionally $0.2 \mathrm{mM}$ and $0.5 \mathrm{mM}$ for bupropion and naphyrone). Treatment with $0.5 \%$ Triton X-100 was used as a positive control. After $24 \mathrm{~h}, 50 \mu \mathrm{l}$ of the ToxiLight assay buffer was added to $20 \mu \mathrm{l}$ of supernatant and luminescence was measured with a Tecan M200 Pro Infinity plate reader (Männedorf, Switzerland) after $5 \mathrm{~min}$ incubation. The luminescence signal was then compared to medium control.

\subsection{ATP Content in HepG2 cells}

The ATP content was assessed with the CellTiter-Glo Luminescent Cell Viability Assay from Promega (Dübendorf, Switzerland) according to the manufacturer's manual. Briefly, 25,000 HepG2 cells per well were seeded in a 96well plate and cultured overnight. The cells were then treated for $24 \mathrm{~h}$ with $100 \mu \mathrm{l}$ of the test substances dissolved in medium (concentrations as for cytotoxicity). Treatment with $0.5 \%$ Triton X-100 was used as a positive control. Thereafter, $50 \mu$ of the supernatant was discarded and $50 \mu \mathrm{l}$ of CellTiter-Glo reagent was added to each well. The plate was then shaken for $15 \mathrm{~min}$ at room temperature to induce cell lysis. Thereafter, the luminescent signal was measured with a Tecan M200 Pro Infinity plate reader and compared with medium control. 
HepaRG cells were cultured and differentiated as follows. 10,000 cells per well were seeded in a 96-well plate and the growth medium was replaced with fresh medium every 3-4 days for 2 weeks. Thereafter, the medium was replaced with medium containing $2 \%$ of DMSO in order to differentiate the cells into cholangiocyteand hepatocyte-like cells. The medium was again replaced with fresh medium every 3-4 days for 2 weeks and finally replaced with medium containing no DMSO and only $2 \%$ FCS. After three days, the medium of some cell preparations was replaced with the same medium containing $20 \mu \mathrm{M}$ rifampicin (Sigma Aldrich) every $24 \mathrm{~h}$ for cytochrome P450 (CYP) induction. The uninduced cell preparations were treated identically with medium not containing rifampicin. After $72 \mathrm{~h}$, the cells were treated with the test drugs $(0.01 \mathrm{mM}, 0.1 \mathrm{mM} 1 \mathrm{mM}$, and $2 \mathrm{mM})$, medium control or $0.5 \%$ Triton $\mathrm{X}-100$. The treatment and experimental procedures were the same as described for HepG2 cells.

\subsection{Mitochondrial membrane potential}

The mitochondrial membrane potential $\left(\Delta \psi_{\mathrm{m}}\right)$ can be regarded as a global indicator of mitochondrial function (Felser et al., 2013). Tetramethylrhodamine methyl ester (TMRM; Thermo Scientific, Wohlen, Switzerland) staining was used to measure $\Delta \psi_{\mathrm{m}}$. TMRM is a non-cytotoxic cationic red-orange fluorescent dye that permeates into the mitochondria. 150,000 HepG2 cells were cultured in a 24-well plate overnight and then treated for $24 \mathrm{~h}$ with $500 \mu \mathrm{l}$ of medium containing the test drugs $(0.01 \mathrm{mM}$, $0.1 \mathrm{mM} 0.2 \mathrm{mM}, 0.5 \mathrm{mM}$, and $1 \mathrm{mM}$ ). The uncoupling agent trifluoromethoxy carbonylcyanide phenylhydrazone (FCCP, Sigma Aldrich) at a concentration of $9 \mu \mathrm{M}$ served as a positive control. After treatment, the cells were washed with phosphatebuffered saline (PBS, Invitrogen) and detached with 0.05\% trypsin-EDTA (Invitrogen) at $37^{\circ} \mathrm{C} .500 \mu \mathrm{l}$ medium were added to the wells and the content was then transferred into polypropylene tubes. The cells were centrifuged at $1500 \mathrm{~g}$ for $2.5 \mathrm{~min}$, washed with PBS and centrifuged again. The supernatant was removed and the cells 
were re-suspended in PBS containing 100 nM TMRM. After 20 minutes of incubation at $37{ }^{\circ} \mathrm{C}$ in the dark, the cells were centrifuged at $300 \mathrm{~g}$ for $5 \mathrm{~min}$, re-suspended in $300 \mu \mathrm{l}$ PBS, and transferred into polypropylene microtubes. Fluorescence (FL-2) of 10,000 live cells was measured with a FACSCalibur flow cytometer (Becton Dickinson, Allschwil, Switzerland).

\subsection{Cellular total glutathione content}

Glutathione is an important antioxidant agent; the cellular total glutathione (tGSH) pool consists of reduced (GSH) and oxidized (GSSG) glutathione. Oxidation of GSH is a defense mechanism against cellular stress and a decrease in the GSH content makes cells more vulnerable to toxic agents. The tGSH content was determined with the enzymatic recycling method described by (Rahman et al., 2006). The assay is based on the oxidation of GSH by 5,5'-dithio-bis(2-nitrobenzoic acid) (DTNB), which is reduced to the yellow 5'-thio-2-nitrobenzoic acid. Briefly, 750,000 HepG2 cells per well were seeded in a 6-well plate and left to attach overnight. The following day, the cells were treated with $1 \mathrm{ml}$ of test drugs dissolved in medium. After $24 \mathrm{~h}$, the cells were washed twice with $1 \mathrm{ml}$ of cold PBS and then harvested with $0.05 \%$ trypsin-EDTA. Culture medium was added, the cell suspension was transferred into pre-chilled polypropylene tubes, and centrifuged at $1000 \mathrm{~g}$ and $4{ }^{\circ} \mathrm{C}$ for $5 \mathrm{~min}$. The supernatant was discarded and the cells re-suspended in cold PBS. The cells were centrifuged again and re-suspended in $1 \mathrm{ml}$ of cold extraction buffer (0.1\% Triton X-100 and $0.6 \%$ sulfosalicylic acid in $0.1 \mathrm{M}$ potassium phosphate buffer with 5 mM EDTA disodium salt, pH 7.5 [KPE]). After two freeze-thaw cycles, the cells were centrifuged at $3000 \mathrm{~g}$ and $4{ }^{\circ} \mathrm{C}$ for $4 \mathrm{~min}$ and the supernatant was then immediately transferred into a fresh polypropylene tube. At this point, the cell extracts could be frozen at $-80^{\circ} \mathrm{C}$ until further use for up to 10 days. To measure tGSH, $20 \mu \mathrm{l}$ of standards (0.103-26.4 $\mu \mathrm{M} \mathrm{GSH}$ in KPE and blank) and $20 \mu \mathrm{l}$ of the cell extracts were added to a 96-well plate. $100 \mu$ of a DTNB-glutathione reductase (GR) solution 
(2 mg DTNB and $10 \mu \mathrm{l}$ of GR [9.5 mg protein/ml; 189 units/mg protein] in $6 \mathrm{ml} \mathrm{KPE)}$ were added to each well. After 30 seconds, $50 \mu$ l of a $\beta$-nicotinamide adenine dinucleotide 2'-phosphate ( $\beta$-NADPH) solution (2 mg of $\beta$-NADPH tetrasodium salt hydrate in $3 \mathrm{ml}$ of KPE) was added to each well. Immediately thereafter, the absorbance at $412 \mathrm{~nm}$ was measured with a Tecan M200 Pro Infinity plate reader every $0.5 \mathrm{~min}$ for $2 \mathrm{~min}$. The protein content was determined with the Pierce Protein Assay Kit (Thermo Fisher) and the tGSH content was then adjusted to protein.

\subsection{Oxygen consumption}

The oxygen consumption rate (OCR) was measured with a Seahorse XF24 extracellular flux assay kit (Seahorse Biosciences, North Billerica, MA, USA). 100,000 HepG2 cells per well were seeded in a Seahorse XF24 cell culture microplate coated with poly-D-lysine. The following day, the cells were treated with the test drugs. After $24 \mathrm{~h}$, the medium was removed and the cells were washed with unbuffered DMEM (4 mM L-glutamate, $1 \mathrm{mM}$ pyruvate, $1 \mathrm{~g} / \mathrm{l}$ glucose, $63.3 \mathrm{mM}$ sodium chloride, $\mathrm{pH} 7.4$ ), pre-warmed to $37^{\circ} \mathrm{C}$. Thereafter, unbuffered DMEM was added to the cells and the plate was incubated for 40 min at $37{ }^{\circ} \mathrm{C}$ in a $\mathrm{CO}_{2}$ free incubator. The ports of the XF24 assay cartridge were then loaded with oligomycin, FCCP, or rotenone in order to reach a final concentration of $1 \mu \mathrm{M}$ for each of these compounds. The XF24 Assay cartridge was loaded into a Seahorse XF24 Analyzer (Seahorse Biosciences) and the program was run according to the instructions. The oxidative leak was determined after inhibition of the mitochondrial phosphorylation by oligomycin and the maximal respiration was determined after stimulation of the electron transport chain by FCCP. Extramitochondrial respiration was determined after complex I inhibition by rotenone and subtracted from basal, leak, and maximal respiration. The protein content was determined using sulforhodamine B (SRB) staining. The cells were fixed with $100 \mu \mathrm{l}$ of $50 \%(\mathrm{w} / \mathrm{v})$ trichloroacetic acid (TCA) added directly to the assay medium of each well. After incubation for $1 \mathrm{~h}$ at $4{ }^{\circ} \mathrm{C}$, the 
cells were washed with deionized water and then stained with $0.4 \%(\mathrm{w} / \mathrm{v}$, in $1 \%[\mathrm{v} / \mathrm{v}]$ acetic acid) SRB. After $20 \mathrm{~min}$, the cells were rapidly washed with $1 \%(\mathrm{v} / \mathrm{v})$ acetic acid and the incorporated dye was solubilized with $100 \mu \mathrm{l}$ of $10 \mathrm{mM}$ TRIS base. The absorbance was then measured at $490 \mathrm{~nm}$.

\subsection{Activity of specific enzyme complexes of the mitochondrial electron transport chain}

The activity of specific enzyme complexes of the mitochondrial respiratory chain was analyzed using an Oxygraph-2k high-resolution respirometer equipped with DataLab software (Oroboros instruments, Innsbruck, Austria). HepG2 cells were treated with test drugs for $24 \mathrm{~h}$ and afterwards re-suspended in MiR05 (mitochondrial respiration medium containing $0.5 \mathrm{mM}$ EGTA, $3 \mathrm{mM}$ magnesium chloride, $20 \mathrm{mM}$ taurine, $10 \mathrm{mM}$ potassium dihydrogen phosphate, $20 \mathrm{mM}$ HEPES, $110 \mathrm{mM}$ sucrose, $1 \mathrm{~g} / \mathrm{l}$ fatty-acid free bovine serum albumin, and $60 \mathrm{mM}$ lactobionic acid, $\mathrm{pH}$ 7.1). The cells were then transferred into the pre-calibrated Oxygraph chamber (Pesta and Gnaiger, 2012). Digitonin (10 $\mu \mathrm{g} / 1$ million cells) was used to permeabilize the cells. Complexes I and III were analyzed using L-glutamate and malate (10 and $2 \mathrm{mM}$, respectively) as substrates followed by the addition of adenosine-diphosphate (ADP; $2.5 \mathrm{mM})$ and rotenone $(0.5 \mu \mathrm{M})$ as an inhibitor of complex I. Duroquinol $(0.5 \mathrm{mM})$ was then added as a substrate of complex III. Complexes II and IV were analyzed using succinate $(10 \mathrm{mM})$ as substrate and rotenone $(0.5 \mu \mathrm{M})$ as a complex I inhibitor, followed by the addition of ADP $(2.5 \mathrm{mM})$. After the addition of the complex III inhibitor antimycin A $(2.5 \mu \mathrm{M}), \quad \mathrm{N}, \mathrm{N}, \mathrm{N}^{\prime}, \mathrm{N}^{\prime}$-tetramethyl-1,4-phenylendiamine and ascorbate $(0.5$ and $2 \mathrm{mM}$, respectively) were added to investigate complex IV activity. The absence of a stimulatory effect of exogenous cytochrome $c(10 \mu \mathrm{M})$ on respiration confirmed integrity of the outer mitochondrial membrane. Protein content 
was determined with the Pierce Protein Assay Kit. Respiration was expressed as oxygen consumption per mg protein.

\subsection{ROS production}

ROS production was determined with the red mitochondrial superoxide $\left(\mathrm{O}_{2}{ }^{-}\right)$ indicator MitoSOX (Invitrogen) according to the manufacturer's manual. MitoSOX red is a live-cell permeant fluorogenic dye that targets the mitochondria and exhibits red fluorescence upon oxidation by superoxide. The seeding and treatment conditions were the same as described for cytotoxicity and ATP assays with HepG2 cells; however, $50 \mu \mathrm{M}$ amidarone was used as a positive control. Briefly, $100 \mu \mathrm{l}$ of MitoSOX reagent $(2.5 \mu \mathrm{M})$ were added to each well of the 96-well plate and incubated for $10 \mathrm{~min}$ at $37^{\circ} \mathrm{C}$ in the dark. After that, the fluorescence was measured at 510/580 nm with a Tecan M200 Pro Infinity plate reader. The protein content was assessed with the Pierce Protein Assay Kit.

\subsection{Lactate Determination}

Lactate concentrations in the cell culture assay were determined with an enzymatic assay after protein precipitation (Olsen, 1971). Briefly, $50 \mu \mathrm{l}$ of supernatant from the MitoSOX assay were diluted with $50 \mu \mathrm{l}$ of $6 \%(\mathrm{v} / \mathrm{v})$ perchloric acid (PCA), vortexed, and centrifuged at $3000 \mathrm{~g}$ for $15 \mathrm{~min}$. Reagent buffer consisting of $100 \mu \mathrm{l}$ hydrazine buffer (6.8 mM EDTA, $100 \mathrm{mM}$ hydrazine sulphate $1 \mathrm{M}$ hydrazine hydrate, pH 9), $0.2 \mathrm{mg} \mathrm{NAD}^{+}$(free acid; Roche diagnostics, Rotkreuz, Switzerland) and $1 \mu \mathrm{LDH}(5 \mathrm{mg} / \mathrm{ml}$; Roche diagnostics) were added to $10 \mu \mathrm{l}$ of sample in a 96well plate. After $30 \mathrm{~min}$ incubation at room temperature, the absorbance was measured and compared to a lactic acid standard curve.

\subsection{Statistics}

Data are presented as mean \pm SEM and statistical analyses were performed 
using GraphPad Prism 6 (GraphPad Software, La Jolla, CA, USA). The activity of the enzyme complexes of the mitochondrial electron transport chain was compared to vehicle control with an unpaired two-tailed Student's $t$-test. For the remaining assays, means were compared to control and differences between control and test drugs were calculated with ANOVA followed by Dunett's test. P-values below 0.05 were considered statistically significant.

\section{Results}

\subsection{Cytotoxicity and ATP content in HepG2 cells}

AK release and cellular ATP content were determined as markers for cytotoxicity and mitochondrial function, respectively. In HepG2 cells after $24 \mathrm{~h}$ of exposure, all cathinones were cytotoxic and decreased the cellular ATP content in a concentration-dependent manner (Fig. 2a-d; Fig. 3a, 3b; Table 1). Bupropion was cytotoxic starting at $2 \mathrm{mM}$ while a decrease in ATP was observed already at $0.5 \mathrm{mM}$ (Fig. 2a). For MDPV, we observed cytotoxicity starting at $2 \mathrm{mM}$ and a decrease in ATP already at $1 \mathrm{mM}$ (Fig. 2b). Mephedrone was cytotoxic starting at $2 \mathrm{mM}$ and decreased ATP at $1 \mathrm{mM}$ (Fig. 2c). Naphyrone was cytotoxic at $0.5 \mathrm{mM}$ and decreased ATP levels at $0.2 \mathrm{mM}$ (Fig. 2d). For methedrone, we observed cytotoxicity and a decrease in ATP content starting at $2 \mathrm{mM}$ (Fig. 3a). Methylone was cytotoxic at $2 \mathrm{mM}$ without significant alteration in ATP content (Fig. 3b). In summary, a decrease in the cellular ATP content at non-cytotoxic drug concentrations, which is compatible with mitochondrial toxicity (Felser et al., 2013; Kamalian et al., 2015), was observed for bupropion, MDPV, mephedrone, and naphyrone.

\subsection{Cytotoxicity and ATP content in HepaRG cells}

HepaRG were less susceptible than HepG2 cells to the toxicants investigated. After $24 \mathrm{~h}$ of drug exposure, we observed cytotoxicity only for bupropion 
and naphyrone and a decrease in ATP content additionally for MDPV (Fig. 2a, 2b, $2 \mathrm{~d}$; Table 1). Bupropion was cytotoxic starting at $2 \mathrm{mM}$ with a decrease in the ATP content at $1 \mathrm{mM}$ (Fig. 2a). MDPV decreased ATP at starting $2 \mathrm{mM}$ without being cytotoxic (Fig. 2b). For naphyrone, we observed cytotoxicity and a decrease in ATP content starting at $1 \mathrm{mM}$ (Fig. 2d). As in HepG2 cells, bupropion and MDPV decreased ATP content at non-cytotoxic drug concentrations, underlining possible mitochondrial toxicity for these toxicants (Felser et al., 2013; Kamalian et al., 2015). Induction of drug-metabolizing enzymes with $20 \mu \mathrm{M}$ rifampicin (Berger et al., 2016) prior to treatment with the toxicants did not cause a difference in cytotoxicity or decrease in the ATP content compared to non-induced cells (data not shown). Since CYP induction in HepaRG cells did not seem to play a major role in toxicity and HepG2 cells were more sensitive to the toxicants, we decided to continue our investigations in HepG2 cells only.

\subsection{Effect on mitochondrial membrane potential}

Next, we determined the effect of the synthetic cathinones on the mitochondrial membrane potential $\left(\Delta \psi_{\mathrm{m}}\right)$ to further investigate a possible role of mitochondria in cellular ATP reduction. HepG2 cells treated for $24 \mathrm{~h}$ showed a decreased $\Delta \psi_{\mathrm{m}}$ for bupropion, MDPV, and naphyrone (Fig. 4a, 4b, 4f). Bupropion reduced the $\Delta \psi_{\mathrm{m}}$ starting at $0.5 \mathrm{mM}$ (Fig. 4a), MDPV at $1 \mathrm{mM}$ (Fig. 4b), and naphyrone at $0.2 \mathrm{mM}$ (Fig. 4f). Mephedrone, methedrone, and methylone did not cause a decrease of $\Delta \psi_{\mathrm{m}}$ at concentrations up to $1 \mathrm{mM}$ (Fig. $4 \mathrm{c}, 4 \mathrm{~d}, 4 \mathrm{e}$ ). The uncoupler FCCP $(9 \mu \mathrm{M})$ that we included as positive control reduced the $\Delta \psi_{\mathrm{m}}$ by $42 \%$ (data not shown).

\subsection{Effect on cellular oxygen consumption}

A decrease in cellular ATP and $\Delta \psi_{\mathrm{m}}$ can be caused by impairment and/or uncoupling of the mitochondrial respiratory chain (Felser et al., 2013; Krähenbühl, 
2001). We therefore assessed the effect of cathinones on the mitochondrial respiratory chain using a XF24 analyzer. Considering the observed decrease in the cellular ATP content at non-cytotoxic concentrations and/or decreased $\Delta \psi_{\mathrm{m}}$, we tested bupropion, MDPV, mephedrone, and naphyrone at various concentrations (Fig. 5a-d). Bupropion caused an increase in leak respiration at $0.8 \mathrm{mM}$ (Fig. 5a), suggesting uncoupling of oxidative phosphorylation. Mephedrone decreased the basal respiration at $1 \mathrm{mM}$ and the maximal respiration at 0.5 and $1 \mathrm{mM}$ (Fig. 5c). Naphyrone decreased the maximal respiration at $0.05 \mathrm{mM}, 0.1 \mathrm{mM}$, and $0.2 \mathrm{mM}$ (Fig. 5d). MDPV decreased the maximal respiration as well, but without reaching statistical significance (Fig. 5b).

As shown, methedrone and methylone neither decreased ATP at non-cytotoxic concentrations (Fig. 3a, 3b) nor did they disrupt $\Delta \psi_{\mathrm{m}}$ (Fig. 4d, 4e). We therefore investigated the oxygen consumption of these substances only at the highest noncytotoxic concentration $(1 \mathrm{mM})$ and we did not find any difference compared to control incubations (data not shown).

We then determined the activity of the complexes of the mitochondrial electron transport chain for bupropion, MDPV, mephedrone, and naphyrone using a highresolution respiratory system (Fig. 6a-h). Bupropion (0.5 mM), MDPV (1 mM), and mephedrone (1 mM) inhibited complex I and complex II activity (Fig. 6a-f). At 0.2 mM, naphyrone inhibited complex I, complex II, and complex III activity (Fig. 6g, 6h).

\subsection{Effect on lactate and ROS production and cellular GSH}

Depending on its extent, the inhibition of the electron transport chain can have several metabolic consequences. Cells try to compensate the loss of mitochondrial ATP production by increasing glycolysis, resulting in increased lactate concentrations in the supernatant, the end product of glycolysis (Felser et al., 2014). In addition, inhibition of complex I and complex III of the electron transport chain can stimulate intra-mitochondrial ROS production (Dröse and Brandt, 2012). 
Accumulating superoxide anion is then metabolized by SOD2 to hydrogen peroxide, which can be reduced by gluthione peroxidase, leading to a decrease in reduced (GSH) and an increase in oxidized glutathione (GSSG). The cellular content of GSH is therefore a measure of oxidative stress (Rahman et al., 2006). Bupropion caused an accumulation of superoxide and lactate at $0.5 \mathrm{mM}$ but without affecting cellular GSH (Fig. 7a). For MDPV, we detected increased lactate concentrations at $1 \mathrm{mM}$ as well as increased superoxide levels which were accompanied by a decrease in GSH at $2 \mathrm{mM}$ (Fig. 7b). Mephedrone stimulated lactate and superoxide production at 1 $\mathrm{mM}$ without a significant decrease in $\mathrm{GSH}$ up to $2 \mathrm{mM}$ (Fig. 7c). Naphyrone stimulated lactate and superoxide production already at $0.2 \mathrm{mM}$ with a simultaneous decrease in GSH (Fig. 7d). Buthionine sulfoximine (BSO), which we used as a positive control, decreased GSH to $14.1 \mathrm{nmol}$ per $\mathrm{mg}$ protein, which corresponds to an $83 \%$ decrease compared to control incubations (data not shown).

\section{Discussion}

Our investigations demonstrate that in HepG2 cells all cathinones investigated were cytotoxic and, except methylone, decreased the cellular ATP content in a concentration-dependent fashion. Bupropion, MDPV, mephedrone, and naphyrone decreased the cellular ATP content at lower concentrations than cytotoxicity occurred, compatible with mitochondrial toxicity. For these substances, impairment of the mitochondrial respiratory chain could be demonstrated directly and/or indirectly (mitochondrial ROS production and lactate production) at similar concentrations as ATP depletion. In HepaRG cells, the compounds investigated were less toxic than in HepG2 cells, but with a similar pattern concerning cytotoxicity and ATP depletion. CYP induction by rifampicin in HepaRG cells did not incease cytotoxcitiy or depletion of the ATP pool. Thus, more active metabolite formation by CYPs did not enhance toxicity. 
Regarding CYP induction, it is however important to be aware that CYP2D6 cannot be induced with rifampicin (Berger et al., 2016). CYP2D6 has been shown to be an important enzyme regarding the metabolism of synthetic cathinones (Helfer et al., 2015; Meyer et al., 2010; Negreira et al., 2015; Pedersen et al., 2013a; Pedersen et al., 2013b) and it is therefore possible that the production of toxic metabolites may have been missed. For instance, the catechol metabolite of MDMA which is formed by CYP2D6, appears to be more hepatotoxic than the parent compound (AntolinoLobo et al., 2011a; Carmo et al., 2006).

In accordance with our results, a recently published study has also shown that HepaRG cells are quite resistant to cytotoxicity elicited by synthetic cathinones, with $\mathrm{EC}_{50}$ concentrations $>2 \mathrm{mM}$ and $>5 \mathrm{mM}$ for MDPV and methylone, respectively, determined through the MTT reduction assay (Valente et al., 2016a). We therefore also used HepG2 cells for our investigations, as they represent a good in vitro model for studying the effect of toxicants on mitochondrial function (Felser et al., 2013; Kamalian et al., 2015). In the current study, cytotoxicity was observed in HepG2 cells for all test drugs in a concentration-dependent manner, which, with the exception of methylone, was accompanied by ATP depletion. For bupropion, MDPV, mephedrone, and naphyrone, ATP depletion was observed at lower concentrations than cytotoxicity, suggesting mitochondrial dysfunction (Felser et al., 2013; Kamalian et al., 2015). For bupropion, MDPV, and naphyrone, ATP depletion was accompanied by a decrease in $\Delta \psi_{\mathrm{m}}$, further supporting the hypothesis that these compounds cause mitochondrial dysfunction. Since a decrease in $\Delta \psi_{\mathrm{m}}$ can be due to impaired activity of the mitochondrial electron transport chain, we investigated the effects of the toxicants on oxidative metabolism of HepG2 cells in more detail. For bupropion, the cellular oxygen consumption in the presence of the complex I substrates L-glutamate and pyruvate revealed an increase in leak respiration, suggesting uncoupling of oxidative phosphorylation. For mephedrone, we observed a decrease in basal and maximal respiration and for naphyrone a decrease in maximal 
respiration, compatible with inhibition of the electron transport chain. For MDPV, there was a numeric decrease in maximal respiration, which did not achieve statistical significance due to a high variation in the control samples. MDPV was associated with an increase in mitochondrial ROS production and cellular generation of lactate, both indirect markers of a decreased function of the mitochondrial electron transport chain and mitochondrial ATP production (Felser et al., 2013; Felser et al., 2014). Using high-resolution respirometry, inhibition of complex I and II of the electron transport chain by bupropion, MDPV, mephedrone, and naphyrone and inhibition of complex III by naphyrone could be shown directly. In comparison, methedrone and methylone did not affect the enzyme complexes of the respiratory chain. Methedrone and methylone did not cause ATP depletion at non-cytotoxic concentrations either, nor did they alter $\Delta \psi_{\mathrm{m}}$ or the cellular oxygen consumption at 1 $\mathrm{mM}$. For methedrone and methylone, effects on mitochondria can therefore most likely not explain cytotoxicity.

The inhibition of complex I and III of the mitochondrial respiratory chain can be associated with increased mitochondrial ROS production (Dröse and Brandt, 2012), which can lead to a reduction of the mitochondrial and cellular GSH stores and opening of the mitochondrial membrane permeability transition pore (Green and Reed, 1998). In the current study, increased ROS production was observed for all mitochondrial toxicants (bupropion, MDPV, mephedrone, and naphyrone), but a significant decrease in the cellular GSH pool was only detected for MDPV and naphyrone. In support of our results, MDPV has previously been shown to stimulate ROS and RNS production and to deplete the cellular GSH stores in primary rat hepatocytes (Valente et al., 2016b).

A second consequence of the inhibition of the mitochondrial function is a shift in the ATP production from mitochondria to glycolysis with a concomitant increase in lactate production (Felser et al., 2014). As expected, the lactate concentration in the supernatant of the incubations containing one of the four compounds affecting 
mitochondrial function increased significantly, paralleling the increase in ROS production (Fig. 7).

Among the four compounds affecting mitochondrial function, bupropion has most often been associated with liver injury (Alonso Rodriguez et al., 2010; Alvaro et al., 2001; Carlos Titos-Arcos et al., 2008; Hu et al., 2000; Humayun et al., 2007; Khoo et al., 2003). The results of the current study suggest that this may more likely be due to the broad use of this compound as a drug than due to a more pronounced mitochondrial toxicity compared to the other cathinones investigated. Bupropion was the only compound, however, that not only inhibited complex I and II of the electron transport chain, but also uncoupled oxidative phosphorylation, which may increase its toxicity.

For all compounds investigated, hepatic toxicity is a rare, but potentially lifethreatening event. Certain factors may therefore increase the probability to develop liver injury when ingesting these compounds. One of these factors is the dose, as suggested by the concentration-dependent toxicity observed in the current study. Other factors reported in the literature suggested to increase the risk of liver toxicity include polydrug abuse and hyperthermia (Armenian et al., 2013; Borek and Holstege, 2012; Dias da Silva et al., 2013a; Dias da Silva et al., 2013b; Green et al., 2004; Prosser and Nelson, 2012). CYP2D6 activity could also play a role, since, as discussed previously, the catechol metabolites of methylenedioxy cathinones (MDPV and methylone in the current study) may be more toxic than the respective parent compounds (Antolino-Lobo et al., 2011a; Carmo et al., 2006). CYP2D6 ultrarapid metabolizers may therefore be at risk for hepatotoxicity associated with these compounds. If mitochondrial dysfunction is a main toxicological mechanism, as suggested by the current study, also preexisting mitochondrial dysfunction may render patients more suceptible. This has been shown for severe hepatotoxicity induced by valproic acid, where preexisting mitochondrial dysfunction is an established suceptibility factor (Krahenbuhl et al., 2000; Stewart et al., 2010). 
Blood concentrations determined in drug users or post mortem cases were typically lower than the toxic concentrations in our cellular assays (Cawrse et al., 2012; Cosbey et al., 2013; Torrance and Cooper, 2010; Wikström et al., 2010). However, a case with post-mortem mephedrone blood concentrations $>100 \mu \mathrm{M}$ has been described (Torrance and Cooper, 2010) and in a series of methylone associated fatalities, drug concentrations in the liver were higher than in the blood, with an average liver-to-blood ratio of 2.68 (Cawrse et al., 2012). Moreover, HepG2 cells appear to be more robust to toxicants than human hepatocytes (Gerets et al., 2012) and the presence of suceptibility factors may shift the blood or liver concentration-toxicity curve to lower concentrations.

In conclusion, our investigations give a closer insight into the mechanism of cathinone-induced hepatotoxicity and demonstrate that bupropion, MDPV, mephedrone and naphyrone are associated with mitochondrial dysfunction due to interactions with enzyme complexes of the electron transport chain. Since liver injury is rare in persons ingesting these compounds, users with liver injury have to have risk factors rendering them more suceptible.

Financial support: The study was supported by a grant from the Swiss National Science foundation to SK (SNF 31003A_156270) 


\section{References}

Alonso Rodriguez, L., Barcina Pajares, R., Fuentes Vigil, J., Gutierrez Gonzalez, A., Rodriguez Perez, L., 2010. [Acute toxic hepatitis secondary to a single dose of bupropion]. Gastroenterol Hepatol 33, 547-549.

Alvaro, D., Onetti-Muda, A., Moscatelli, R., Atili, A.F., 2001. Acute cholestatic hepatitis induced by bupropion prescribed as pharmacological support to stop smoking. A case report. Dig Liver Dis 33, 703-706.

Andreu, V., Mas, A., Bruguera, M., Salmerón, J.M., Moreno, V., Nogué, S., Rodés, J., 1998. Ecstasy: a common cause of severe acute hepatotoxicity. J Hepatol 29, 394-397.

Antolino-Lobo, I., Meulenbelt, J., Molendijk, J., Nijmeijer, S.M., Scherpenisse, P., van den Berg, M., van Duursen, M.B., 2011a. Induction of glutathione synthesis and conjugation by 3,4-methylenedioxymethamphetamine (MDMA) and 3,4dihydroxymethamphetamine (HHMA) in human and rat liver cells, including the protective role of some antioxidants. Toxicology 289, 175-184.

Antolino-Lobo, I., Meulenbelt, J., van den Berg, M., van Duursen, M.B., 2011b. A mechanistic insight into 3,4-methylenedioxymethamphetamine ("ecstasy")-mediated hepatotoxicity. Vet Q 31, 193-205.

Armenian, P., Mamantov, T.M., Tsutaoka, B.T., Gerona, R.R., Silman, E.F., Wu, A.H., Olson, K.R., 2013. Multiple MDMA (Ecstasy) overdoses at a rave event: a case series. J Intensive Care Med 28, 252-258.

Baumann, M.H., Ayestas, M.A., Jr., Partilla, J.S., Sink, J.R., Shulgin, A.T., Daley, P.F., Brandt, S.D., Rothman, R.B., Ruoho, A.E., Cozzi, N.V., 2012. The designer methcathinone analogs, mephedrone and methylone, are substrates for monoamine transporters in brain tissue. Neuropsychopharmacology 37, 1192-1203. 
Baumann, M.H., Partilla, J.S., Lehner, K.R., 2013. Psychoactive "bath salts": not so soothing. Eur J Pharmacol 698, 1-5.

Berger, B., Donzelli, M., Maseneni, S., Boess, F., Roth, A., Krahenbuhl, S., Haschke, M., 2016. Comparison of Liver Cell Models Using the Basel Phenotyping Cocktail. Front Pharmacol 7, 443.

Borek, H.A., Holstege, C.P., 2012. Hyperthermia and multiorgan failure after abuse of "bath salts" containing 3,4-methylenedioxypyrovalerone. Ann Emerg Med 60, 103105.

Carlos Titos-Arcos, J., Hallal, H., Collados, V., Plaza-Aniorte, J., 2008. [Acute hepatitis secondary to bupropion]. Gastroenterol Hepatol 31, 549.

Carmo, H., Brulport, M., Hermes, M., Oesch, F., Silva, R., Ferreira, L.M., Branco, P.S., Boer, D., Remião, F., Carvalho, F., Schön, M.R., Krebsfaenger, N., Doehmer, J., Bastos, M.e.L., Hengstler, J.G., 2006. Influence of CYP2D6 polymorphism on 3,4methylenedioxymethamphetamine ('Ecstasy') cytotoxicity. Pharmacogenet Genomics $16,789-799$.

Carvalho, M., Carmo, H., Costa, V.M., Capela, J.P., Pontes, H., Remião, F., Carvalho, F., Bastos, M.e.L., 2012. Toxicity of amphetamines: an update. Arch Toxicol 86, 1167-1231.

Cawrse, B.M., Levine, B., Jufer, R.A., Fowler, D.R., Vorce, S.P., Dickson, A.J., Holler, J.M., 2012. Distribution of methylone in four postmortem cases. J Anal Toxicol $36,434-439$.

Cosbey, S.H., Peters, K.L., Quinn, A., Bentley, A., 2013. Mephedrone (methylmethcathinone) in toxicology casework: a Northern Ireland perspective. J Anal Toxicol 37, 74-82. 
De Carlis, L., De Gasperi, A., Slim, A.O., Giacomoni, A., Corti, A., Mazza, E., Di

Benedetto, F., Lauterio, A., Arcieri, K., Maione, G., Rondinara, G.F., Forti, D., 2001. Liver transplantation for ecstasy-induced fulminant hepatic failure. Transplant Proc $33,2743-2744$.

Dias da Silva, D., Carmo, H., Lynch, A., Silva, E., 2013a. An insight into the hepatocellular death induced by amphetamines, individually and in combination: the involvement of necrosis and apoptosis. Arch Toxicol 87, 2165-2185.

Dias da Silva, D., Carmo, H., Silva, E., 2013b. The risky cocktail: what combination effects can we expect between ecstasy and other amphetamines? Arch Toxicol 87, $111-122$.

Dröse, S., Brandt, U., 2012. Molecular mechanisms of superoxide production by the mitochondrial respiratory chain. Adv Exp Med Biol 748, 145-169.

Ellis, A.J., Wendon, J.A., Portmann, B., Williams, R., 1996. Acute liver damage and ecstasy ingestion. Gut 38, 454-458.

Felser, A., Blum, K., Lindinger, P.W., Bouitbir, J., Krahenbuhl, S., 2013. Mechanisms of hepatocellular toxicity associated with dronedarone--a comparison to amiodarone. Toxicol Sci 131, 480-490.

Felser, A., Lindinger, P.W., Schnell, D., Kratschmar, D.V., Odermatt, A., Mies, S., Jenö, P., Krähenbühl, S., 2014. Hepatocellular toxicity of benzbromarone: effects on mitochondrial function and structure. Toxicology 324, 136-146.

Fröhlich, S., Lambe, E., O'Dea, J., 2011. Acute liver failure following recreational use of psychotropic "head shop" compounds. Ir J Med Sci 180, 263-264. 
Garbino, J., Henry, J.A., Mentha, G., Romand, J.A., 2001. Ecstasy ingestion and fulminant hepatic failure: liver transplantation to be considered as a last therapeutic option. Vet Hum Toxicol 43, 99-102.

Gerets, H.H., Tilmant, K., Gerin, B., Chanteux, H., Depelchin, B.O., Dhalluin, S., Atienzar, F.A., 2012. Characterization of primary human hepatocytes, HepG2 cells, and HepaRG cells at the mRNA level and CYP activity in response to inducers and their predictivity for the detection of human hepatotoxins. Cell Biol Toxicol 28, 69-87.

Green, A.R., O'Shea, E., Colado, M.I., 2004. A review of the mechanisms involved in the acute MDMA (ecstasy)-induced hyperthermic response. Eur J Pharmacol 500, 313.

Green, D.R., Reed, J.C., 1998. Mitochondria and apoptosis. Science 281, 13091312.

Helfer, A.G., Turcant, A., Boels, D., Ferec, S., Lelievre, B., Welter, J., Meyer, M.R., Maurer, H.H., 2015. Elucidation of the metabolites of the novel psychoactive substance 4-methyl-N-ethyl-cathinone (4-MEC) in human urine and pooled liver microsomes by GC-MS and LC-HR-MS/MS techniques and of its detectability by GCMS or LC-MS(n) standard screening approaches. Drug Test Anal 7, 368-375.

Hu, K.Q., Tiyyagura, L., Kanel, G., Redeker, A.G., 2000. Acute hepatitis induced by bupropion. Dig Dis Sci 45, 1872-1873.

Humayun, F., Shehab, T.M., Tworek, J.A., Fontana, R.J., 2007. A fatal case of bupropion (Zyban) hepatotoxicity with autoimmune features: Case report. J Med Case Rep 1, 88.

Jones, A.L., Jarvie, D.R., McDermid, G., Proudfoot, A.T., 1994. Hepatocellular damage following amphetamine intoxication. J Toxicol Clin Toxicol 32, 435-444. 
Kamalian, L., Chadwick, A.E., Bayliss, M., French, N.S., Monshouwer, M., Snoeys, J., Park, B.K., 2015. The utility of HepG2 cells to identify direct mitochondrial dysfunction in the absence of cell death. Toxicol In Vitro 29, 732-740.

Kamijo, Y., Soma, K., Nishida, M., Namera, A., Ohwada, T., 2002. Acute liver failure following intravenous methamphetamine. Vet Hum Toxicol 44, 216-217.

Khoo, A.L., Tham, L.S., Lee, K.H., Lim, G.K., 2003. Acute liver failure with concurrent bupropion and carbimazole therapy. Ann Pharmacother 37, 220-223.

Krähenbühl, S., 2001. Mitochondria: important target for drug toxicity? J Hepatol 34, 334-336.

Krahenbuhl, S., Brandner, S., Kleinle, S., Liechti, S., Straumann, D., 2000.

Mitochondrial diseases represent a risk factor for valproate-induced fulminant liver failure. Liver 20, 346-348.

Liechti, M., 2015. Novel psychoactive substances (designer drugs): overview and pharmacology of modulators of monoamine signaling. Swiss Med Wkly 145, w14043.

Meltzer, P.C., Butler, D., Deschamps, J.R., Madras, B.K., 2006. 1-(4-Methylphenyl)2-pyrrolidin-1-yl-pentan-1-one (Pyrovalerone) analogues: a promising class of monoamine uptake inhibitors. J Med Chem 49, 1420-1432.

Meyer, M.R., Du, P., Schuster, F., Maurer, H.H., 2010. Studies on the metabolism of the alpha-pyrrolidinophenone designer drug methylenedioxy-pyrovalerone (MDPV) in rat and human urine and human liver microsomes using GC-MS and LC-highresolution MS and its detectability in urine by GC-MS. J Mass Spectrom 45, 14261442.

Negreira, N., Erratico, C., Kosjek, T., van Nuijs, A.L., Heath, E., Neels, H., Covaci, A., 2015. In vitro Phase I and Phase II metabolism of alpha-pyrrolidinovalerophenone 
(alpha-PVP), methylenedioxypyrovalerone (MDPV) and methedrone by human liver microsomes and human liver cytosol. Anal Bioanal Chem 407, 5803-5816.

Olsen, C., 1971. An enzymatic fluorimetric micromethod for the determination of acetoacetate, -hydroxybutyrate, pyruvate and lactate. Clin Chim Acta 33, 293-300.

Pedersen, A.J., Petersen, T.H., Linnet, K., 2013a. In vitro metabolism and pharmacokinetic studies on methylone. Drug Metab Dispos 41, 1247-1255.

Pedersen, A.J., Reitzel, L.A., Johansen, S.S., Linnet, K., 2013b. In vitro metabolism studies on mephedrone and analysis of forensic cases. Drug Test Anal 5, 430-438.

Pesta, D., Gnaiger, E., 2012. High-resolution respirometry: OXPHOS protocols for human cells and permeabilized fibers from small biopsies of human muscle. Methods Mol Biol 810, 25-58.

Prosser, J.M., Nelson, L.S., 2012. The toxicology of bath salts: a review of synthetic cathinones. J Med Toxicol 8, 33-42.

Rahman, I., Kode, A., Biswas, S.K., 2006. Assay for quantitative determination of glutathione and glutathione disulfide levels using enzymatic recycling method. Nat Protoc 1, 3159-3165.

Rickli, A., Hoener, M.C., Liechti, M.E., 2015. Monoamine transporter and receptor interaction profiles of novel psychoactive substances: para-halogenated amphetamines and pyrovalerone cathinones. Eur Neuropsychopharmacol 25, 365376.

Simmler, L.D., Buser, T.A., Donzelli, M., Schramm, Y., Dieu, L.H., Huwyler, J., Chaboz, S., Hoener, M.C., Liechti, M.E., 2013. Pharmacological characterization of designer cathinones in vitro. $\mathrm{Br} \mathrm{J}$ Pharmacol 168, 458-470. 
Simmler, L.D., Rickli, A., Hoener, M.C., Liechti, M.E., 2014. Monoamine transporter and receptor interaction profiles of a new series of designer cathinones.

Neuropharmacology 79, 152-160.

Stewart, J.D., Horvath, R., Baruffini, E., Ferrero, I., Bulst, S., Watkins, P.B., Fontana, R.J., Day, C.P., Chinnery, P.F., 2010. Polymerase gamma gene POLG determines the risk of sodium valproate-induced liver toxicity. Hepatology 52, 1791-1796.

Torrance, H., Cooper, G., 2010. The detection of mephedrone (4methylmethcathinone) in 4 fatalities in Scotland. Forensic Sci Int 202, e62-63.

Valente, M.J., Araujo, A.M., Bastos Mde, L., Fernandes, E., Carvalho, F., Guedes de Pinho, P., Carvalho, M., 2016a. Editor's Highlight: Characterization of Hepatotoxicity Mechanisms Triggered by Designer Cathinone Drugs (beta-Keto Amphetamines). Toxicol Sci 153, 89-102.

Valente, M.J., Araujo, A.M., Silva, R., Bastos Mde, L., Carvalho, F., Guedes de Pinho, P., Carvalho, M., 2016b. 3,4-Methylenedioxypyrovalerone (MDPV): in vitro mechanisms of hepatotoxicity under normothermic and hyperthermic conditions. Arch Toxicol 90, 1959-1973.

Wikström, M., Thelander, G., Nyström, I., Kronstrand, R., 2010. Two fatal intoxications with the new designer drug methedrone (4-methoxymethcathinone). J Anal Toxicol 34, 594-598. 
Figure legends

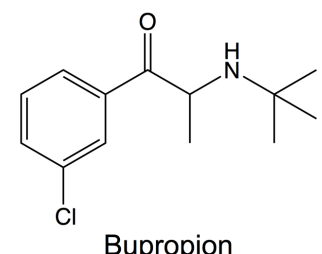

Bupropion<smiles>CNC(C)C(=O)c1ccc(OC)cc1</smiles>

Methedrone<smiles>CC(N)C(=O)c1ccccc1</smiles>

Cathinone<smiles>CCCC(C(=O)c1ccc2c(c1)OCO2)N1CCCC1</smiles>

MDPV<smiles>CNC(C)C(=O)c1ccc2c(c1)OCO2</smiles>

Methylone<smiles>CNC(C)C(=O)c1ccc(C)cc1</smiles>

Mephedrone<smiles>CCCC(C(=O)c1ccc2ccccc2c1)N1CCCC1</smiles>

Fig. 1. Structures of the synthetic cathinones used in the study. 

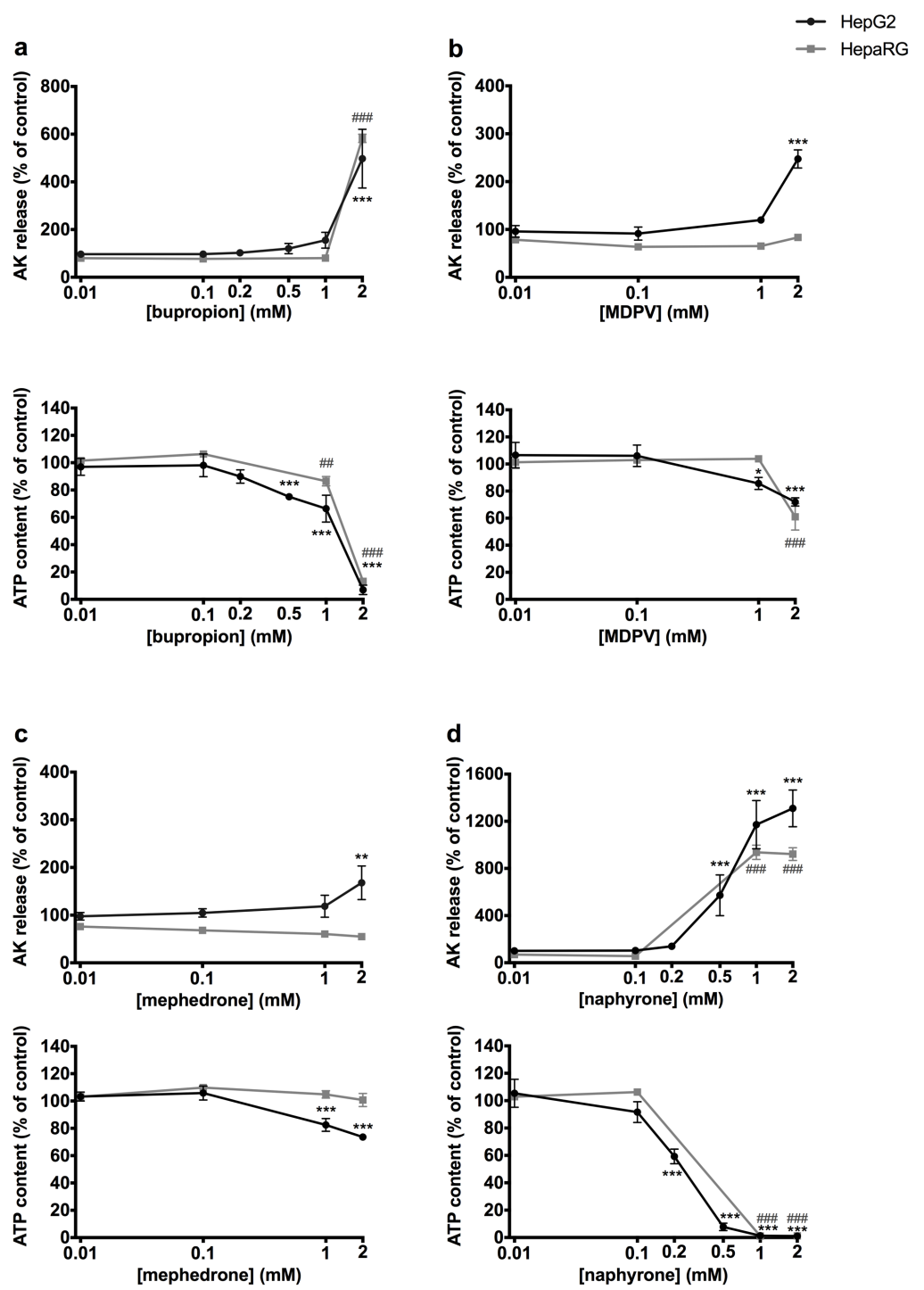

Fig. 2. Effect on the intracellular ATP content preceding cytotoxicity.

Intracellular ATP content and cytotoxicity expressed as release of adenylate kinase after drug exposure for $24 \mathrm{~h}$ in HepG2 and non-induced HepaRG cells. Data are expressed as mean \pm SEM of at least three independent experiments. Differences between control and test drugs were calculated with ANOVA followed by Dunett's test. Significance levels for HepG2 cells are given as ${ }^{*} p<0.05,{ }^{* *} p<0.01,{ }^{* *} p<0.001$. Significance levels for HepaRG cells are given as ${ }^{\#} p<0.01,{ }^{\# \#} p<0.001$. 

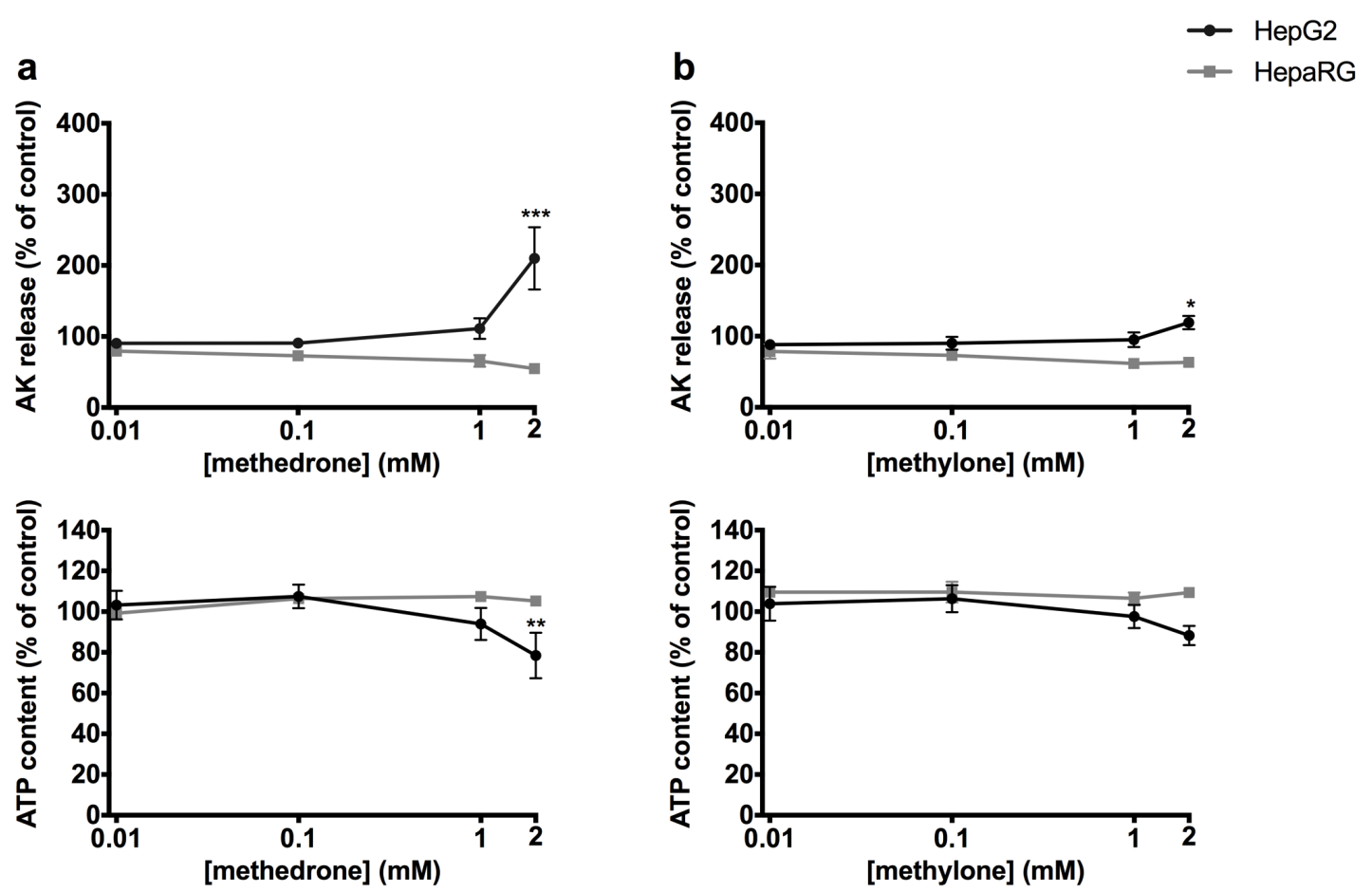

Fig. 3. No effect on the intracellular ATP content preceding cytotoxicity.

Intracellular ATP content and cytotoxicity expressed as release of adenylate kinase after drug exposure for $24 \mathrm{~h}$ in HepG2 and non-induced HepaRG cells. Data are expressed as mean \pm SEM of at least three independent experiments. Differences between control and test drugs were calculated with ANOVA followed by Dunett's test. Significance levels for HepG2 cells are given as ${ }^{*} p<0.05,{ }^{* *} p<0.01,{ }^{* * *} p<0.001$. 
a

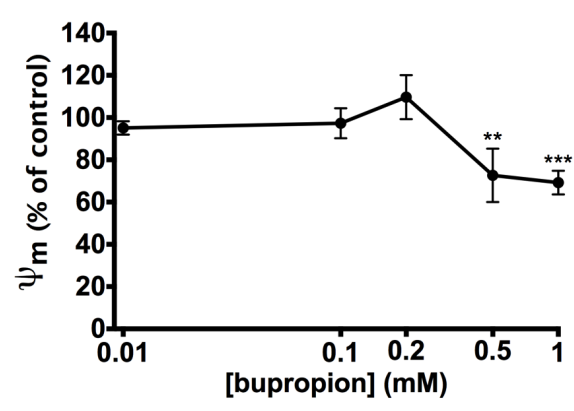

c

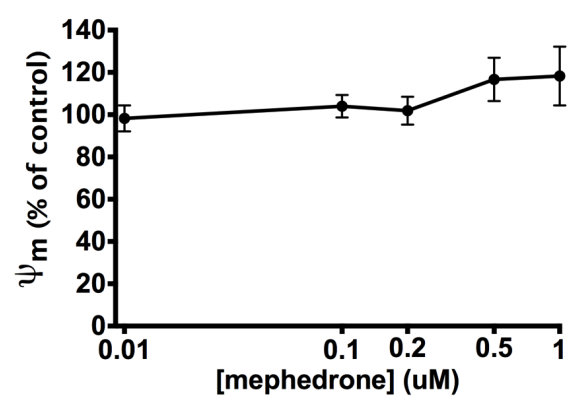

e

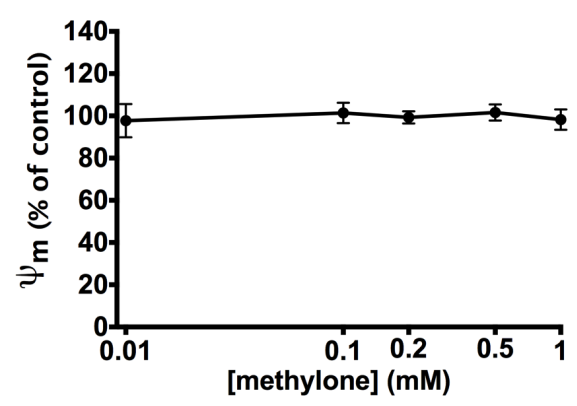

b

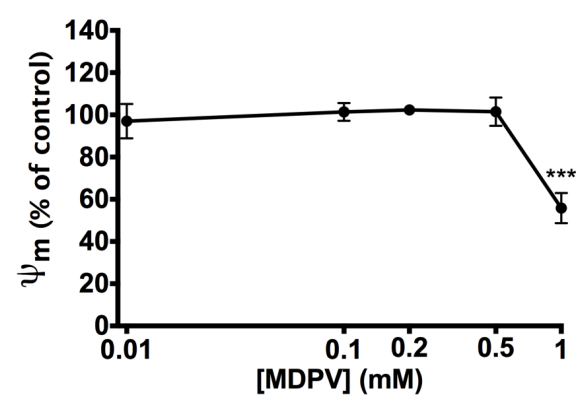

d

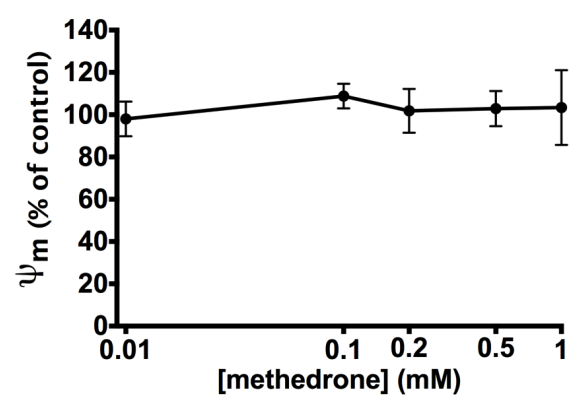

f

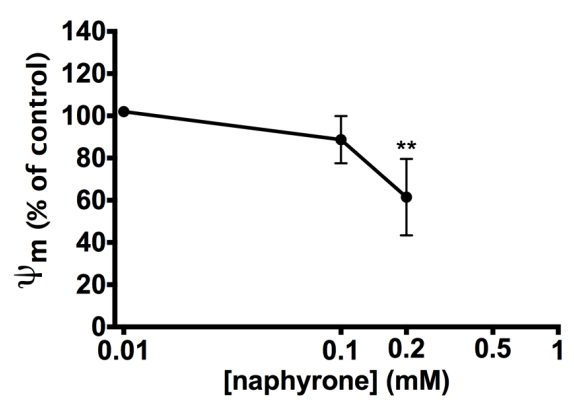

Fig. 4. Effect on mitochondrial membrane potential of HepG2 cells.

Mitochondrial membrane potential after $24 \mathrm{~h}$ drug exposure expressed as mean \pm SEM of at least three independent experiments compared to vehicle control.

Differences between control and test drugs were calculated with ANOVA followed by Dunett's test. Significance levels are given as ${ }^{* *} p<0.01,{ }^{* * *} p<0.001$. 

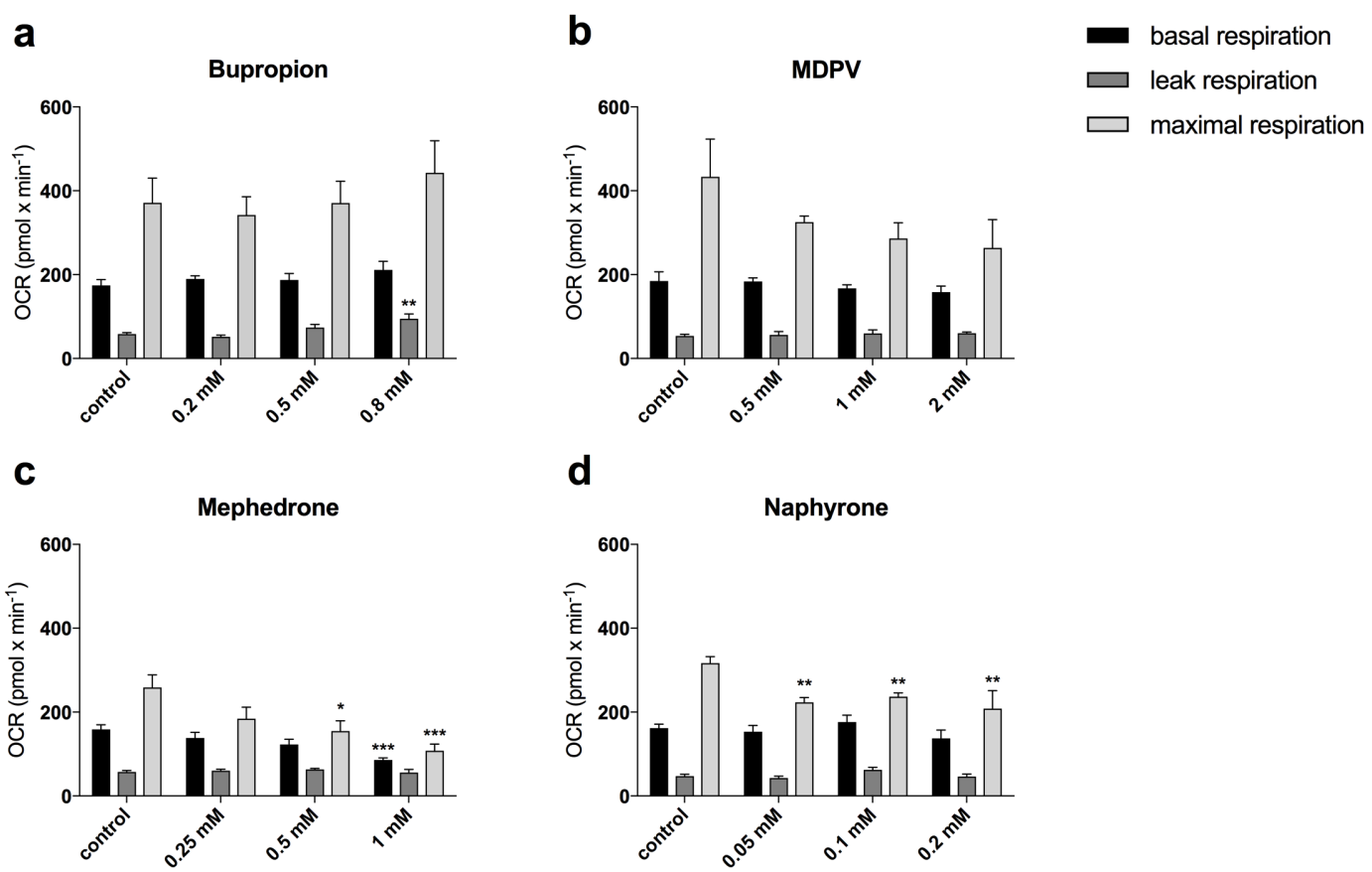

Fig. 5. Function of the respiratory chain in HepG2 cells.

Oxygen consumption rate (OCR) in HepG2 cells after 24 h drug exposure. Data are expressed as mean \pm SEM of at least four independent experiments. Basal respiration, leak respiration, and maximal respiration were determined after drug treatment as specified in Methods and were compared to the respective vehicle control values. Statistical significance was calculated with ANOVA followed by Dunett's test and significance levels are given as ${ }^{*} p<0.05,{ }^{* *} p<0.01,{ }^{* * *} p<0.001$. 


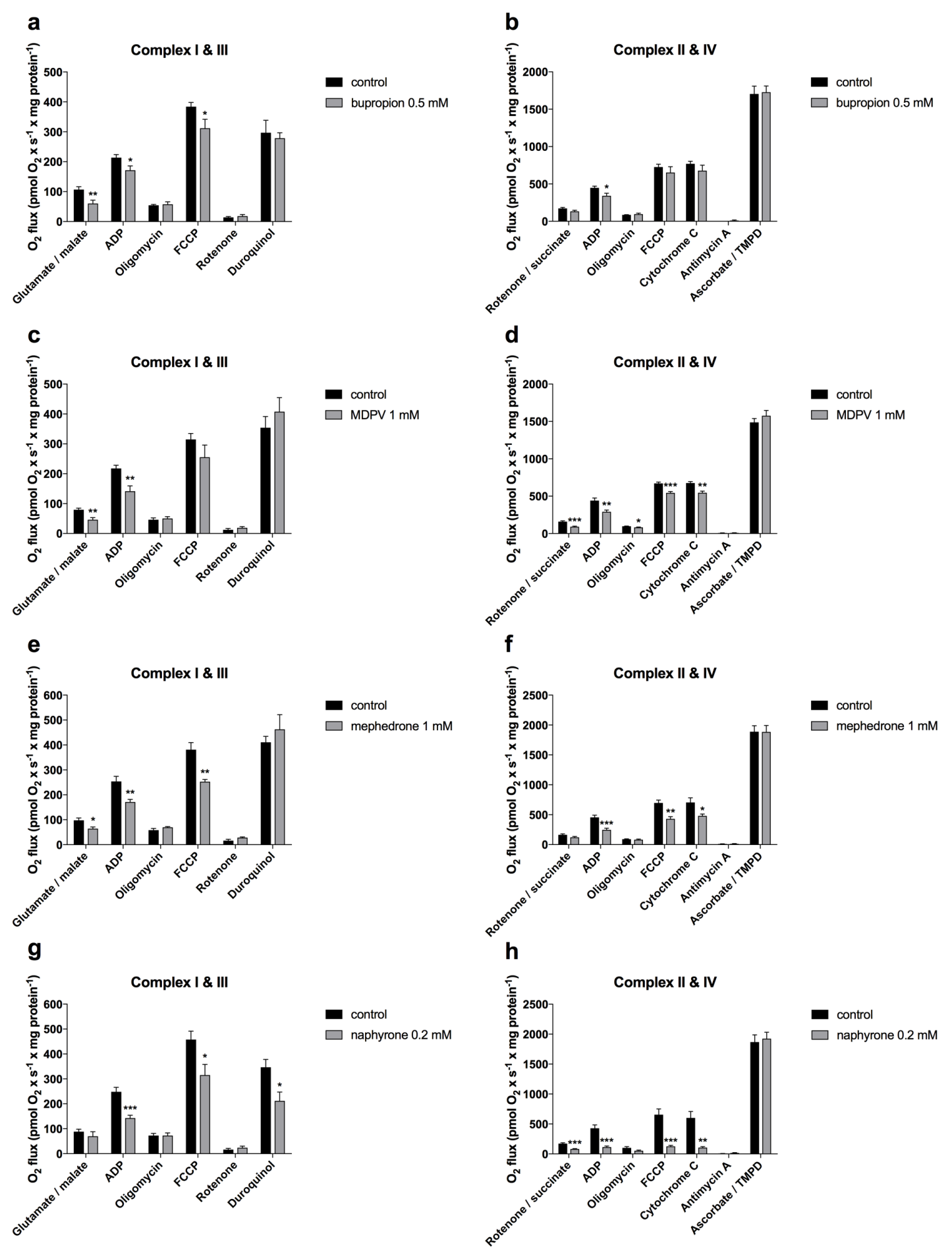

Fig. 6. Effect on the activity of the enzyme complexes of the mitochondrial electron transport chain measured using the Oxygraph-2k-high-resolution respirometer in HepG2 cells.

Respiratory capacities of HepG2 cells after $24 \mathrm{~h}$ treatment of bupropion ( $\mathrm{a}, \mathrm{b}), \mathrm{MDPV}$ $(c, d)$, mephedrone $(e, f)$, and naphyrone $(g, h)$. Data are expressed as mean $\pm S E M$ 
of at least six independent experiments. Treatment was compared to vehicle control with an unpaired two-tailed Student's $t$-test. Significance levels are given as ${ }^{*} p<0.05$, ${ }^{* *} p<0.01,{ }^{* * *} p<0.001$

a
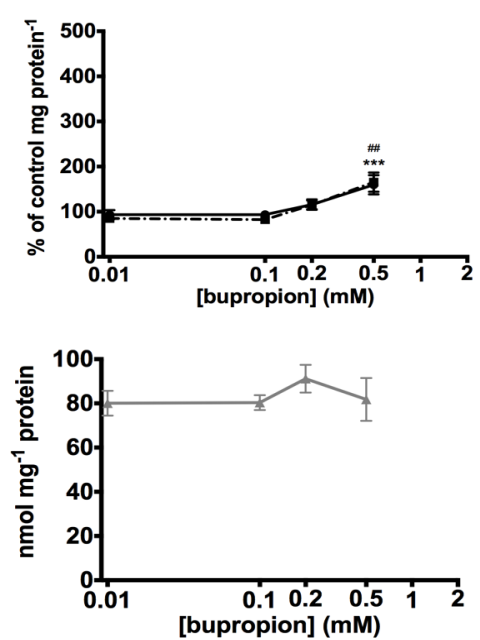

C
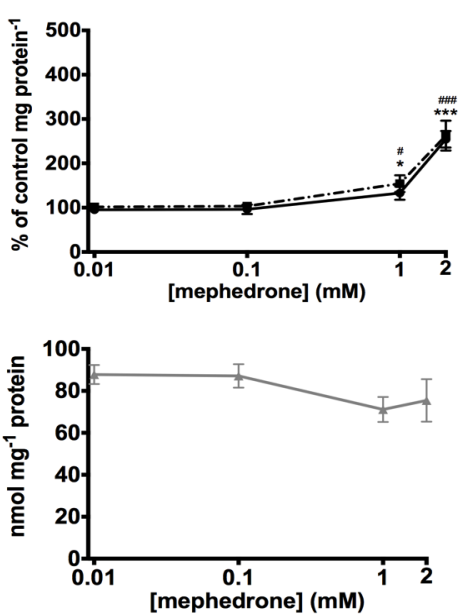

b
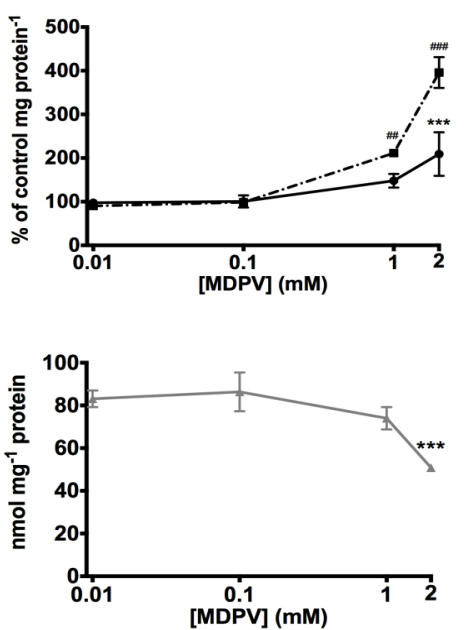

d
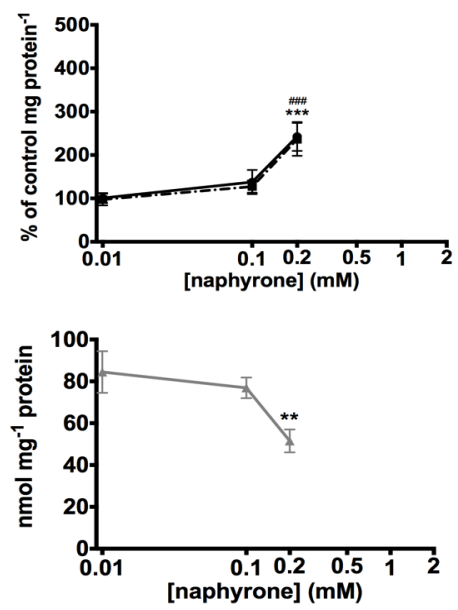

Fig. 7. Cellular stress and tGSH content in HepG2 cells

Superoxide production, lactate concentrations and total GSH levels after $24 \mathrm{~h}$ drug treatment. Data are expressed as mean \pm SEM of at least three independent experiments compared to vehicle control. Statistical significance was calculated with ANOVA followed by Dunett's test and significance levels are given as ${ }^{*} p<0.05$, ${ }^{* *} p<0.01,{ }^{* * *} p<0.001$ for superoxide production and GSH and ${ }^{\# \#} p<0.01,{ }^{\# \#} p<0.001$ for lactate production. 
Table 1. Summary of the toxicity associated with the cathinones investigated.

\begin{tabular}{|c|c|c|c|c|c|c|}
\hline & $\begin{array}{l}\text { Bupropion } \\
(\mathrm{mM})\end{array}$ & $\begin{array}{l}\text { MDPV } \\
(\mathrm{mM})\end{array}$ & $\begin{array}{l}\text { Mephedrone } \\
(\mathrm{mM})\end{array}$ & $\begin{array}{l}\text { Methedrone } \\
(\mathrm{mM})\end{array}$ & $\begin{array}{l}\text { Methylone } \\
(\mathrm{mM})\end{array}$ & $\begin{array}{l}\text { Naphyrone } \\
(\mathrm{mM})\end{array}$ \\
\hline \multicolumn{7}{|l|}{ HepaRG cells } \\
\hline Cytotoxicity & 2 & & & & & 1 \\
\hline ATP depletion & 1 & 2 & & & & 1 \\
\hline \multicolumn{7}{|l|}{ HepG2 cells } \\
\hline Cytotoxicity & 2 & 2 & 2 & 2 & 2 & 0.5 \\
\hline ATP depletion & 0.5 & 1 & 1 & 2 & & 0.2 \\
\hline Decrease of $\Delta \psi_{\mathrm{m}}$ & 0.5 & 1 & & & & 0.2 \\
\hline Superoxide production & 0.5 & 2 & 1 & & & 0.2 \\
\hline Lactate production & 0.5 & 1 & 1 & & & 0.2 \\
\hline GSH depletion & & 2 & & & & 0.2 \\
\hline Complex I disruption & 0.5 & 1 & 1 & & & 0.2 \\
\hline Complex II disruption & 0.5 & 1 & 1 & & & 0.2 \\
\hline Complex III disruption & & & & & & 0.2 \\
\hline Complex IV disruption & & & & & & \\
\hline
\end{tabular}

The concentrations (mM) indicated in the Table correspond to the lowest concentration where a significant toxic effect was recorded. The data are obtained from Fig. 2 to Fig. 7. Where no concentration is listed, no significant toxicity was observed in the concentration range investigated. 